\title{
Assessing HIV/AIDS Knowledge, Awareness, and Attitudes among Senior High School Students in Kuwait
}

\author{
AlMunther Alhasawi Saroj Bala Grover Ali Sadek Ibrahim Ashoor \\ Iqbal Alkhabbaz Sameh Almasri \\ Department of Medicine, Infectious Diseases Hospital, Ministry of Health, Kuwait City, Kuwait
}

\section{Highlights}

- Knowledge about HIV is the key strategy utilized in the prevention and control of HIV/AIDS worldwide, and data from Kuwait are sparse. This study assesses the knowledge, awareness, and attitude about HIV/AIDS among senior high school students in Kuwait. The observations of this study will serve as a basis for further tailored approaches to strategic programs to control this disease in Kuwait.

\section{Keywords}

Human immunodeficiency virus/acquired immune deficiency syndrome $\cdot$ High school students $\cdot$ Kuwait

\begin{abstract}
Objectives: An estimated 1.8 million individuals worldwide became newly infected with human immunodeficiency virus (HIV) in 2016, which amounts to 5,000 new infections per day. This includes 160,000 children. The HIV epidemic not only affects the health of individuals but also impacts households, communities, and the development and economic growth of nations [1]. The prevention and control of HIV infection and acquired immune deficiency syndrome (AIDS) are recognized as a national priority in Kuwait. This study assesses the knowledge, awareness, and attitudes about HIV/
\end{abstract}

AIDS among senior high school students in Kuwait. Materials and Methods: A cross-sectional study was conducted in a convenience sample of 346 students in 8 randomly selected high schools in 3 governorates of Kuwait, using a questionnaire designed to measure the student's knowledge and attitude towards HIV/AIDS. The survey questionnaire was administered to the students in their classrooms. Results: This study revealed that the students were knowledgeable with regard to the nature and mode of transmission of HIV/ AIDS, but they needed a more detailed understanding of the disease to prevent stigmatization and discrimination of an infected person. Conclusion: This study provides a benchmark for further elaborate studies in the community to develop appropriate health education and awareness programs.

(c) 2019 The Author(s)

Published by S. Karger AG, Basel

\begin{tabular}{ll}
\hline KARGER & $\begin{array}{l}\text { () } 2019 \text { The Author(s) } \\
\text { Published by S. Karger AG, Basel }\end{array}$ Operger \\
$\begin{array}{l}\text { E-Mail karger@karger.com } \\
\text { www.karger.com/mpp }\end{array}$ & $\begin{array}{l}\text { This is an Open Access article licensed under the Creative Commons } \\
\text { Attribution-NonCommercial-4.0 International License (CC BY-NC) } \\
\text { (http://www.karger.com/Services/OpenAccessLicense), applicable to } \\
\text { the online version of the article only. Usage and distribution for com- } \\
\text { mercial purposes requires written permission. }\end{array}$
\end{tabular}

AlMunther Alhasawi

Department of Medicine, Infectious Diseases Hospital PO Box 5

Kuwait City 1300 (Kuwait)

E-Mail awalhasawi@moh.gov.kw 
Table 1. The questionnaire

Q1. Is HIV transmitted by handshakes?

Q2. Is HIV transmitted by normal kissing?

Q3. Is HIV transmitted by sharing syringes with drug users?

Q4. Is HIV transmitted via sexual relations without protection?

Q5. Can a person infected with HIV live without symptoms for many years?

Q6. If you know that a person infected with HIV is selling vegetables, would you buy from him or her?

Q7. Would you accept a student infected with HIV attending the same school as you?

Q8. Can use of the same barber tools transmit HIV?

Q9. Can a person infected with HIV live outside of a hospital without isolation?

Q10. Mention 2 ways to prevent HIV

$\begin{array}{ll}\text { Yes } & \text { No } \\ \text { Yes } & \text { No } \\ \text { Yes } & \text { No } \\ \text { Yes } & \text { No } \\ \text { Yes } & \text { No } \\ \text { Yes } & \text { No } \\ & \\ \text { Yes } & \text { No } \\ \text { Yes } & \text { No } \\ \text { Yes } & \text { No }\end{array}$

\section{Introduction}

The human immunodeficiency virus (HIV) has emerged as the single most formidable challenge to public health, human rights, and development in the new millennium [1, 2]. Spreading knowledge and awareness about HIV is one of the key strategies utilized in the prevention and control of HIV/AIDS worldwide. Inadequate knowledge and risky practices are major hindrances in preventing the spread of HIV. In many countries, sexually transmitted diseases (STD) and unplanned pregnancies are frequently observed among adolescents. During the last century, and especially during the last few decades of that century, the early onset of puberty and initiation of sexual relationships were observed to occur at decreasing ages in many industrialized nations, whereas the average age of marriage increased. Thus, many adolescents began having sexual relationships with one or multiple sexual partners prior to marriage, and this facilitated the spread of STD and HIV. In many countries a significant proportion of youth initiate sexual activity by the age of 15 years [3]. Thus, adolescents in general are at a higher risk of contracting HIV through sexual transmission. Youth aged 13-14 years accounted for more than 1 in 5 new diagnoses in 2015 [4].

Adolescents in Kuwait represented $11.5 \%$ of the total population as of January 2017. Kuwait is a conservative Islamic society. It is still taboo to talk openly about sex-related topics. Hence, it becomes even more important to fathom the knowledge and attitude of the young towards HIV/ AIDS. Furthermore, this data could serve as a basis for a tailored approach to a strategic disease control program [5].

In Kuwait, there is a paucity of data regarding awareness of HIV among adolescents. The aim of this study was to survey HIV-related knowledge and attitudes toward HIV and AIDS- infected individuals among high school students in Kuwait.

\section{Subjects and Methods}

There are 6 governorates and 141 governmental high schools in Kuwait. Of these, 64 are for male students and 77 are for female students. The total number of high school students during the study period was 73,832; of these 63,379 were Kuwaiti and 10,553 were non-Kuwaiti [6]. A cross-sectional study was conducted in a student population from 8 randomly selected high schools in 3 governorates in Kuwait in April 2017. Students from 10th to the 12th grade were included in this study. A total of 346 students (both boys and girls) were enrolled. This was a convenience sample.

\section{Tools for Data Collection}

A questionnaire (Table 1) designed to measure the student's knowledge and attitude towards HIV/AIDS was used as a tool for data collection. The questionnaire consisted of 7 questions pertaining to knowledge about various aspects of HIV/AIDS and 3 questions to examine their attitude towards the disease.

Consent was obtained from the principals of the schools and the Ministry of Health and Ministry of Education. The entire questionnaire was explained to the students who self-completed it, staying completely anonymous. Only verbal consent was taken from the participating students in the presence of their teachers.

\section{Statistical Methodology}

The questionnaire was validated via the content validation approach, as 4 experts familiar with AIDS/HIV were consulted to approve the 10 questions and their scale. Data were collected, coded, and then entered into an IBM-compatible computer using SPSS version 24 for Windows. Entered data were checked for accuracy and normality using Kolmogorov-Smirnov and Shapiro-Wilk tests. The data were found to be not normally distributed. A 75\% agreement of the type of question was the cut-off point for distribution of the questions into knowledge and attitude. Reliability was tested using Cronbach's a coefficient (i.e., 0.823 for the knowledge part and 0.754 for the attitude part). Qualitative variables were expressed as numbers and percents while quantitative variables were expressed as medians as a measure of central tendency. IQR were used as a measure of dispersion. Two scores were computed, i.e., one for total knowledge (Q1 + Q2 + Q3 + Q4 + Q5 + Q8 + Q10) and the other for total attitude or stigma- and discrimination-related questions (Q6 + Q7 + Q9). These were based on the UNAIDS global AIDS monitoring report and indicators (2017). 
Table 2. Distribution of the study sample according to their general characteristics

\begin{tabular}{lrr}
\hline Variable & $n$ & $\%$ \\
\hline School No. & & \\
1 & 47 & 13.6 \\
2 & 67 & 19.4 \\
3 & 66 & 19.1 \\
4 & 42 & 12.1 \\
5 & 40 & 11.6 \\
6 & 38 & 11.0 \\
7 & 27 & 7.8 \\
8 & 19 & 5.5 \\
Sex & & \\
Female & 154 & 44.5 \\
Male & 192 & 55.5 \\
Nationality & & \\
Kuwaiti & 322 & 93.1 \\
Non-Kuwaiti & 19 & 5.5 \\
Bedoon & 5 & 1.4 \\
Grade & & 15.9 \\
10th & 55 & 17.1 \\
11th & 59 & 67.1 \\
12th & 232 & 38.2 \\
Specialty & 132 & 46.0 \\
Science & 159 & \\
Literature & 291 & \\
Total & 55 & \\
Missing & & \\
\hline
\end{tabular}

The total number of senior students is 346 .

For independent samples, the Mann-Whitney's U test (or $Z$ test) was used as a nonparametric test of significance for comparison between 2 sample medians (for sex and specialty). The Kruskal-Wallis test ( $\chi^{2}$ value) was used as a nonparametric test of significance for one-way comparisons between more than 2 samples means when the one-way ANOVA test was not appropriate. $p<$ 0.05 was considered statistically significant.

\section{Results}

A total of 346 senior students, both boys and girls, from 8 different schools located in 3 governorates of Kuwait were enrolled into this study. Of the 346 students, 192 (55.5\%) were male. The majority were Kuwaiti (93.1\%), while 5.5\% were non-Kuwaiti and $1.4 \%$ were bedoons (stateless). Around $15.9 \%$ of the participants were in the 10th grade, $17.1 \%$ were in the 11 th grade, and $67.1 \%$ were in the 12 th grade. Of these, $38.2 \%$ of the participants were from the science stream and $46 \%$ were from arts stream whereas $15.9 \%$ did not reveal their major subject of study (Table 2).
Table 3. Distribution of the study sample according to their responses to the questions about awareness and knowledge about HIV

\begin{tabular}{lcc}
\hline Question & $n$ & $\%$ \\
\hline Q1. Is HIV transmitted by handshakes? & 58 & \\
Wrong & 284 & 82.1 \\
Correct & 342 & 98.8 \\
Total & 4 & 1.2 \\
Missing & & \\
\hline Q2. Is HIV transmitted by normal kissing? & 194 & 56.1 \\
Wrong & 142 & 41.0 \\
Correct & 336 & 97.1 \\
Total & 10 & 2.9 \\
Missing & & \\
\hline
\end{tabular}

Q3. Is HIV transmitted by sharing syringes with drug users?

$\begin{array}{lll}\text { Wrong } & 44 & 12.7\end{array}$

$\begin{array}{lll}\text { Correct } & 295 & 85.3\end{array}$

$\begin{array}{lll}\text { Total } & 339 & 98.0\end{array}$

$\begin{array}{lll}\text { Missing } & 7 & 2.0\end{array}$

Q4. Is HIV transmitted via sexual relations without protection?

Wrong $\quad 13 \quad 3.8$

$\begin{array}{lrr}\text { Correct } & 325 & 93.9\end{array}$

$\begin{array}{llr}\text { Total } & 338 & 97.7\end{array}$

Missing $\quad 8 \quad 2.3$

Q5. Can a person infected with HIV live without symptoms for many years?

\begin{tabular}{lrc} 
Wrong & 161 & 46.5 \\
Correct & 178 & 51.4 \\
Total & 339 & 98.0 \\
Missing & 7 & 2.0 \\
\hline Q8. Can use of the same barber tools transmit $H I V ?$ & \\
Wrong & 141 & 40.8 \\
Correct & 202 & 58.4 \\
Total & 343 & 99.1 \\
Missing & 3 & 9 \\
\hline Q10. Mention 2 ways to prevent HIV & & \\
Wrong answer & 154 & 44.5 \\
1 correct answer & 109 & 31.5 \\
2 correct answers & 83 & 24.0 \\
Total & 346 & 100.0 \\
\end{tabular}

With regard to the knowledge of students about modes of transmission of HIV, the majority (82.1\%) did not consider that shaking hands with an affected individual could transmit the disease, whereas $16.8 \%$ thought that it could. More than two fifths (41\%) of the students believed that kissing could transmit the disease; $56 \%$ assumed that it was not transmitted by kissing and $2.9 \%$ did not give their opinion (Table 3 ). 
Table 4. Total knowledge scores of the studied students according to demographics

\begin{tabular}{|c|c|c|c|c|c|}
\hline Variable & Subjects, $n$ & Median & IQR & Test value & $p$ \\
\hline \multicolumn{6}{|l|}{ Gender } \\
\hline Female & 154 & 4.0 & $3.5-5.0$ & 4.182 & 0.001 \\
\hline Male & 192 & 5.0 & $4.0-6.0$ & & \\
\hline \multicolumn{6}{|l|}{ Nationality } \\
\hline Kuwaiti & 322 & 4.5 & $4.0-5.5$ & 20.119 & 0.001 \\
\hline \multicolumn{6}{|l|}{ Non- } \\
\hline Kuwaiti & 19 & 6.0 & $5.5-7.0$ & & \\
\hline Bedoon & 5 & 5.5 & $4.0-6.0$ & & \\
\hline \multicolumn{6}{|l|}{ School No. } \\
\hline 1 & 47 & 3.8 & $3.0-4.5$ & 73.175 & 0.001 \\
\hline 2 & 67 & 4.5 & $4.0-5.0$ & & \\
\hline 3 & 66 & 5.5 & $4.1-6.0$ & & \\
\hline 4 & 42 & 4.0 & $3.0-4.0$ & & \\
\hline 5 & 40 & 4.5 & $3.5-6.0$ & & \\
\hline 6 & 38 & 5.0 & $4.5-5.8$ & & \\
\hline 7 & 27 & 5.0 & $4.5-5.5$ & & \\
\hline 8 & 19 & 5.5 & $4.0-6.1$ & & \\
\hline \multicolumn{6}{|l|}{ Grade } \\
\hline 10th & 55 & 4.5 & $4.0-5.0$ & 1.661 & 0.436 \\
\hline 11th & 59 & 4.5 & $4.0-5.5$ & & \\
\hline 12 th & 232 & 4.5 & $3.5-6.0$ & & \\
\hline \multicolumn{6}{|l|}{ Specialty } \\
\hline Sciences & 132 & 5.5 & $4.5-6.0$ & 7.165 & 0.001 \\
\hline Arts & 159 & 4.0 & $3.0-5.0$ & & \\
\hline
\end{tabular}

Additionally, $58.4 \%$ of the respondents felt that sharing barber tools might transmit the disease; $40.8 \%$ assumed that it would be not transmitted by such a practice and $0.8 \%$ refrained from answering this question (Q8 in Table 3)

The majority of the students $(85.3 \%)$ knew that sharing a syringe is a mode of transmission (Q3 in Table 3). Students were also questioned about the course of the disease. About $51.4 \%$ knew that an HIV-infected person can remain asymptomatic for many years (Q5 in Table 3).

The overall knowledge about HIV among the study population was higher in males than in females $(p=$ $0.000)$. Students in the science stream had a statistically higher total knowledge score compared to students in arts stream $(p=0.001$; Table 4$)$.

In reply to the questions regarding stigma and discrimination, the majority (74.6\%) stated that they would not buy vegetables from an infected vegetable vendor. About 59.5\% refused to share the class with an infected person, and $52.6 \%$ felt that a person infected with HIV does not require isolation in a hospital and can stay outside of a hospital. (Q6, Q7, and Q9 in Table 5). Male and female students showed no difference in their attitude to-
Table 5. Distribution of the study sample according to responses to the questions about attitudes toward HIV/AIDS-infected persons

\begin{tabular}{lcc}
\hline Question & $n$ & $\%$ \\
\hline Q6. If you know that a person infected with HIV is selling vegeta- \\
bles, would you buy from him or her? \\
Wrong & 258 & 74.6 \\
Correct & 84 & 24.3 \\
Total & 342 & 98.8 \\
Missing & 4 & 1.2
\end{tabular}

Q7. Would you accept a student infected with HIV attending the same school as you?

$\begin{array}{lrr}\text { Wrong } & 206 & 59.5 \\ \text { Correct } & 135 & 39.0 \\ \text { Total } & 341 & 98.6 \\ \text { Missing } & 5 & 1.4\end{array}$

Q9. Can a person infected with HIV live outside of a hospital without isolation?

\begin{tabular}{lrr} 
Wrong & 160 & 46.2 \\
Correct & 182 & 52.6 \\
Total & 342 & 98.8 \\
Missing & 4 & 1.2 \\
\hline
\end{tabular}

wards persons affected with HIV ( $p=0.019)$, but a significant positive attitude was shown towards such people by students in the science stream $(p=0.008$; Table 6$)$.

The participants were asked to suggest 2 methods that would give protection from HIV/AIDS (Q10 in Table 3) as an indicator to judge their knowledge about the disease. The various answers given included abstinence from all sexual contact by being faithful, use of a condom, avoidance of the use of i.v. drugs, not sharing barber tools, use of pre- and postexposure prophylaxis, regular premarital testing, and voluntary HIV testing. Around $31.5 \%$ were able to give 1 correct answer and $24.0 \%$ gave 2 correct answers (Table 3 ).

\section{Discussion}

This study highlights the high awareness of the disease among the students, but it also indicates some significant lacunae in complete understanding of the disease among the population.

Compared to the review of similar studies from different parts of the world, the findings of our study are in general consistent with the findings reported by Uddin et al. [7] and Huda and Amanullah [8] from Bangladeshi students and by Othman [9] from high school students in 
Table 6. Total attitude scores of the studied students according to demographics

\begin{tabular}{lrllll}
\hline Variable & $n$ & Median & IQR & Test value $p$ \\
\hline Gender & & & & & \\
$\quad$ Female & 154 & 1.0 & $0.0-2.0$ & 2.339 & 0.019 \\
$\quad$ Male & 192 & 1.0 & $0.0-2.0$ & & \\
Nationality & & & & & \\
$\quad$ Kuwaiti & 322 & 1.0 & $0.0-2.0$ & 6.954 & 0.031 \\
$\quad$ Non- & & & & & \\
Kuwaiti & 19 & 2.0 & $1.0-3.0$ & & \\
Bedoon & 5 & 0.0 & $0.0-2.0$ & & \\
School No. & & & & & \\
1 & 47 & 0.5 & $0.0-1.0$ & 23.524 & 0.001 \\
2 & 67 & 1.0 & $0.0-2.0$ & & \\
3 & 66 & 1.0 & $0.5-2.0$ & & \\
4 & 42 & 1.0 & $0.5-1.0$ & & \\
5 & 40 & 1.0 & $0.5-2.0$ & & \\
6 & 38 & 1.0 & $0.5-2.0$ & & \\
7 & 27 & 2.0 & $1.0-2.0$ & & \\
8 & 19 & 1.0 & $1.0-2.3$ & & \\
Grade & & & & & \\
10 th & 55 & 2.0 & $1.0-2.0$ & 8.754 & 0.436 \\
11 th & 59 & 1.0 & $0.0-2.0$ & & \\
12 th & 232 & 1.0 & $0.0-2.0$ & & \\
Specialty & & & & & \\
Sciences & 132 & 1.0 & $0.0-2.0$ & 2.633 & 0.008 \\
Arts & 159 & 1.0 & $0.0-2.0$ & & \\
\hline
\end{tabular}

Erbil City, Iraq. In a review of the published literature on awareness and knowledge of STD among school-going adolescents between 13 and 20 years of age in Europe, Samkange-Zeeb et al. [10] reported a high (90\%) awareness about HIV. Macek and Matković [11], in a crosssectional study in Croatia, reported similar observations.

However, our observations differ from those reported by Shirin and Ahmed [12] from another group of students in Bangladesh. They noted that very few students had good knowledge about HIV/AIDS (average knowledge, 56.1\%; poor knowledge, $34.5 \%$; and good knowledge, 9.4\%). Selim and El-Shereef [13] also observed similar low levels of knowledge in secondary technical school students in Assiut, Egypt. Investigators in Nigeria [14] and Nepal [2] observed similar results among secondary school students. Thus, improving the awareness about STD, especially HIV/AIDS, among the youth is a prerequisite for any national control program.

Our study also highlights the awareness among the young about the mode of transmission of HIV/AIDS. In our study $93.9 \%$ of the respondents knew that sexual contact is a means of transmission. The same percentage
(93.7\%) was found in a survey done in Jeddah, Saudi Arabia, in high school students [15]. The majority of participants $(82.1 \%)$ knew that HIV is not transmitted by shaking hands with an infected person. A significant number of students (85.3\%) were aware that HIV is transmitted by sharing syringes used for i.v. administration of drugs. At the same time, educating them on misconceptions about other commonly believed modes of transmission is equally important.

Our observations demonstrate some gaps in the understanding of the disease among the young. More than half of the participants (54.1\%) felt that a person infected with HIV can survive for many years without symptoms and $52.6 \%$ indicated that an infected person can stay outside a hospital without the need for isolation.

Our study underlines the need to educate the public about prevention of HIV/AIDS using time-tested tools. In response to the question which asked to suggest at least 2 means that would give protection from HIV, only $24.5 \%$ of the participants could give 2 correct answers and $31.5 \%$ could give only 1 correct answer. This was another parameter used to judge their knowledge about the disease. Similar observations were noticed in a study conducted among secondary school students in China [16]. In this study, although most students could identify models of HIV transmission, a large proportion of students had misconceptions regarding symptoms, activities that did not transmit the disease, and treatment and preventive measures. In a recent study by Mackman and Hussein [17] in Michigan, USA, the majority of the participants (98\%) knew that HIV is transmitted sexually and by sharing needles, but they expressed misconceptions similar to those in our study. Dehghani et al., [18] also reported similar observations in a study from Shiraz, Iran.

In a comparative study in Kenyan and Swedish teenagers, Eriksson et al. [19] reported that the overall knowledge of HIV was high in both groups. In addition, they were highly aware of the danger of sexual transmission of HIV. This compares well with our study. Swedish students were more knowledgeable about i.v. drug use and homosexuality as risk factors, whereas Kenyan students were more likely to implicate breastfeeding and sex as modes of transmission. Further studies are needed to clarify the knowledge about high-risk factors in our population.

Sachsenweger et al. [20] demonstrated the relevance of imparting better awareness of the disease in Germany. The pupils demonstrated a significant gap in their level of knowledge about methods of infection. More precise knowledge was demonstrated by pupils (60\% of 769 students) following an awareness event compared to $40 \%$ in those who attended no awareness event. 
Our study highlighted many other areas of concern. The majority (74.6\%) indicated that they would not buy vegetables from an infected vendor, and $59.5 \%$ refused to share the same class with an infected student. Discrimination and stigmatization of HIV/AIDS-affected children and adolescents by their schoolmates are well-known as demonstrated by Dehghani et al. [18] in Iran. In contrast, Macek and Matković [11], in a cross-sectional study in Croatia, showed positive attitudes of students toward the integration of children with HIV/AIDS into regular schools. In our study, the students in the science stream showed a more positive attitude and better knowledge about HIV than the students in the arts stream.

Gender differences were also found, as male students showed a better awareness than females. Similar findings have been observed among high school students in Iraq [9] and adolescents in Bangladesh [7]. The possible reason for this could be that male students are probably less hesitant in discussing the taboo subject of HIV with others and hence become better informed.

The most important limitation of this study is its small sample size. However, the observations made in our study may serve as a pilot study for other, more elaborate studies in the future. The consensus that emerged from comparing the various studies is that most students in general have reasonable awareness about the disease but lack thorough knowledge, which influences their attitude of discrimination and stigmatization of affected individuals.

These outcomes highlight the need for a better and more robust education about HIV/AIDS, especially in a setting such as in Kuwait, where talking freely about sex education is not readily accepted. Hence, it becomes even more important to fathom the knowledge and attitude of the young towards HIV/AIDS. The data generated by this preliminary study may be used to plan a more comprehensive study coupled with suitably tailored health education programs for a strategic disease control of STD as well as HIV/AIDS.

\section{Conclusion}

This study provides preliminary data from a country and region where current information on the knowledge of young adults about HIV/AIDS and their attitude toward infected persons are sparse. This study highlights the lack of basic knowledge of HIV/AIDS among young students, modes of transmission, and management; it also indicates that stigma about the disease and discrimination of affected individuals in society is common among students. The basic approach for control and prevention of HIV/AIDS remains prevention through better knowledge and awareness since an effective cure or vaccine is not yet available.

An improved multisectoral approach for HIV/AIDS education is suggested for Kuwait. The National HIV/AIDS control committee and school health programs should come forward to design awareness programs and campaigns tailored to targeting the youth and filling the lacunae in their understanding of HIV/AIDS. Implementations of such programs could be done in a variety of settings including schools, educational institutions, STD clinics, mosques, and public sport facilities and establishments commonly used by the youth and more importantly at the community level. Also future studies should try to explore and clear the common misconceptions about the disease in general, including handling by society.

\section{References}

1 Joint United Nations Program on HIV/AIDS (UNAIDS). Report on the global HIV/AIDS epidemic: UNAIDS publication 02-26 E. Geneva: United Nations; 2002.

2 Jaiswal S, Magar BS, Thakali K, Pradhan A, Gurubacharya DL. HIV/AIDS and STI related knowledge, attitude and practice among high school students in Kathmandu valley. Kathmandu Univ Med J. 2005;3:69b75.

3 Kirby D [Internet]. HIV transmission and prevention in adolescents. San Francisco: UCSF: 2002. Available from: http://hivinsite.ucsf.edu/ InSite/page $=\mathrm{kb}-07-04-03$.

4 HIV Among Youth/CDC. https://www.cdc. gov/hiv/group/age/youth/index.html
5 National HIV/AIDS Strategy for Kuwait 20172021. Ministry of Health in Kuwait; 2017.

6 Central Statistical Bureau Kuwait. Annual report 2017/2018. Kuwait City: Central Statistical Bureau Kuwait; 2019.

7 Uddin MA, Isaramalai S, Thassari J. Knowledge and attitude regarding HIV/AIDS prevention among adolescents in Bangladesh. Paper presented at the 2 nd International Conference on Humanities and Social Sciences, Faculty of Liberal Arts, Prince of Songkhla University, 2010.

8 Huda N, Amanullah A. HIV-AIDS related knowledge among secondary school students in Bangladesh: A cross-sectional study. Adv Infect Dis. 2013;3(4):274-80.
9 Othman SM. Knowledge about HIV/AIDS among high school students in Erbil city/Iraq. Glob J Health Sci. 2014 Jul;7(1):16-23.

10 Macek M, Matković V. Attitudes of school environment towards integration of HIV-positive pupils into regular classes and knowledge about HIV/AIDS: cross-sectional study. Croat Med J. 2005 Apr;46(2):320-5.

11 Samkange-Zeeb FN, Spallek L, Zeeb H. Awareness and knowledge of sexually transmitted diseases (STDs) among school-going adolescents in Europe: a systematic review of published literature. BMC Public Health. 2011 Sep;11(1): 727. 
12 Shirin S, Ahmed S. Knowledge of AIDS among the adolescent students of two selected colleges of Dhaka City. Ibrahim Med Coll J. 2007;1(2): 5-8.

13 Selim MD, El-Shereef EA. Perceptions of secondary technical schools students in Assiut, upper Egypt, about AIDS: effect of an educational intervention. J Family Community Med. 2010 Jan;17(1):3-10.

14 Nwokocha AR, Nwakoby BA. Knowledge, attitude, and behavior of secondary (high) school students concerning HIV/AIDS in Enugu, Nigeria, in the year 2000. J Pediatr Adolesc Gynecol. 2002 Apr;15(2):93-6.
15 AlOtaibi SM, Alabbas FF, Pacha MS. Knowledge and Perceptions of HIV/AIDS among high school students in Jeddah, Saudi Arabia. J AIDS Clin Res. 2016;7(8):595.

16 Zhao Q, Li X, Stanton B, Mao R, Wang J, Zhong $\mathrm{L}$, et al. HIV/AIDS awareness and knowledge among secondary school students in China. World Health Popul. 2010;11(4):38-48.

17 Mackman S, Hussein I. Awareness, knowledge and behavior regarding HIV/AIDS among freshman students at Oakland University. EBMJ. 2017;12:73-6.
18 Dehghani A, Dehghani P, Dehghani B. HIV/ AIDS knowledge and attitude among high school students in Shiraz, Iran. J Midwifery and Reprod Health. 2017;5:897-903.

19 Eriksson T, Sonesson A, Isacsson A. HIV/ AIDS-information and knowledge: a comparative study of Kenyan and Swedish teenagers. Scand J Soc Med. 1997 Jun;25(2):111-8.

20 Sachsenweger M, Kundt G, Hauk G, Lafrenz M, Stoll R. Knowledge of school pupils about the HIV/AIDS topic at selected schools in Mecklenburg-Pomerania: results of a survey of school pupils. Gesundheitswesen 2011 Jan;73(1):e216. 